\title{
Caesarean Section Rate in a Tertiary Hospital in Makurdi, North-Central Nigeria
}

Samuel K Hembah-Hilekaan ${ }^{1 *}$, Austin Ojabo ${ }^{1}$ and Sarah Idogah ${ }^{2}$

${ }^{1}$ Department of Obstetrics and Gynaecology, Benue State University Teaching Hospital, Makurdi, Benue State, Nigeria

${ }^{2}$ Department of Nursing Services, Benue State University Teaching Hospital, Makurdi, Benue State, Nigeria

*Corresponding author: Samuel K Hembah-Hilekaan, Department of Obstetrics and Gynaecology, Benue State University Teaching Hospital, Makurdi, Benue State, Nigeria, Tel: +234-8035722335; E-mail: hemhilsk@yahoo.com

Rec date: March 16, 2015 Acc date: April 13, 2015 Pub date: April 20, 2015

Copyright: (c) 2015 Hilekaan SKH, et al. This is an open-access article distributed under the terms of the Creative Commons Attribution License, which permits unrestricted use, distribution, and reproduction in any medium, provided the original author and source are credited.

\section{Abstract}

Setting: Benue State University Teaching Hospital, Makurdi is a new tertiary health care institution which was established by an Act of the Benue State House of Assembly and started offering clinical services in 2012.

Background: There is widespread concern about the increasing proportion of births by caesarean section (CS) all over the world.

Objectives: This study is to determine the CS rate, the indications, the trend and possible reasons for the rate in a new and emerging tertiary hospital.

Patients and methods: The obstetric and theatre records of all caesarean deliveries that occurred at Benue State University Teaching Hospital, Makurdi, North Central Nigeria, between 1st September, 2002 and 31st August, 2014 were reviewed retrospectively. The total number of deliveries was obtained from labour ward.

Results: There were 636 deliveries, out of which 124 were caesarean sections, giving a CS rate of $19.3 \%$. Majority of the patients (43.5\%) who had CS were in the age group 26-30 years, with (82.3\%) of the total patients included in this study were in the age range of $21-35$ years, with a mean of 28.8 . Of those who had CS (124), $8.9 \%$ were nulliparous while $78.2 \%$ were multiparous. $67.4 \%$ of the women were booked, while $14.7 \%$ were unbooked. Most of the patients (75.9\%) delivered at term (37-42 weeks gestation), $17.9 \%$ delivered preterm and $6.3 \%$ had prolonged pregnancy. Cephalopelvic disproportion (CPD) was the commonest indication for CS (28.8\%), followed by previous CS and fetal distress ( $14.4 \%$ and $12.3 \%$ respectively).

Conclusion: although the CS rate in the developed countries appears to have stabilized and is slowing down, that in developing countries is still high. The CS rate at BSUTH is very high. CPD was the singular most common factor responsible followed by repeat CS and foetal distress. Deliberate attempts to reduce the CS rate should be made.

Keywords: Caesarean section; Rate; Cephalopelvic disproportion; Tertiary hospital; Nigeria

\section{Introduction}

Caesarean section (CS) is one of the commonly performed surgical procedures in obstetrics and is certainly one of the oldest operations in surgery [1]. Caesarean section is a surgical operation to deliver a baby or babies by means of an incision through the abdomen and uterus [2]. The World Health Organization (WHO) stated in 1985 that; "there is no justification for any region to have CS rates higher than $10-15 \%$ " [3]. The recommended minimum CS rate at population level to avoid death and severe morbidity in the mother lays between $1-5 \%$, according to WHO and others [4-6]. On the other hand, studies evaluating the association CS rates with neonatal death have shown outcome improvements up to a CS rate of $10 \%$ [7-9]. Several studies have shown an association between CS rate and maternal and infant mortality at population level in low income countries where large sectors of the population lack access to basic obstetric care $[7,8,10]$. The CS rate above a certain limit have not shown additional benefit for the mother or the baby, and some studies have even shown that high CS rates could be linked to negative consequences in maternal and child health [7-11].

One of the most dramatic features of modern obstetrics is the relentless increase in the CS rate [12], which has been said to become a public health problem because of the increased health risk for both the mother and babies including the high cost of the procedure compared to vagina delivery. In developing countries, attributed factors include fear of litigation, liberal use of CS for breech presentation, detection of foetal distress by continuous electronic foetal monitoring among others [13]. In developing countries like Nigeria, some of the reasons may include high incidence of CPD, repeat CS for patients with previous CS, use of foetal heart rate abnormality for the diagnosis of foetal distress, a change in practice standards that reflects an increasing willingness by specialists to resort to CS, unbooked status of patients and late presentation when CS is the safest mode of and above all the referral nature of our hospitals where most of the operations take place. Some the general factors contributing to the increase are changes in the population of childbearing women, with more older women who have developed medical conditions and more women 
Page 2 of 4

with extra challenges of multiple birth [14]. The availability of safe anaesthesia, the fear of litigation and reports from mothers of pressure by health professionals to accept CS and use of the procedure for nonmedical reasons including financial benefits may play a role in the ever rising incidence, even if minimally.

Researchers have also found out that CS rates have gone up for all categories of birthing women, regardless of age, the number of babies they are having, the extent of health problems, their race/ethnicity or the characteristics [15].

The CS rate at Benue State University Teaching Hospital (BSUTH) Makurdi, North-Central Nigeria has not been previously known. Our objective is therefore to determine the CS trend, rate and to identify some of the factors responsible.

\section{Materials and Methods}

This was a retrospective study of all CS deliveries at BSUTH, Makurdi, North-Central Nigeria between 1st September, 2012 and 31st August, 2014. BSUTH is a newly established Benue State government owned tertiary care hospital, located in Makurdi, North-Central Nigeria. Makurdi is an urban centre and the capital of Benue State located in North-Central, Nigeria. The hospital serves as a referral centre for secondary and primary care hospitals in the public and private sectors and covers a wide area in the region. The obstetric department has several consultants and registrars and serves as a postgraduate training centre for obstetrics and gynaecology. The theatre and labour ward registers of all patients who had CS at BSUTH were checked and their medical records retrieved and analyzed for age, parity, booking status and the indications for CS. Where there was more than one indication, they were analyzed separately. The total number of vagina deliveries was obtained from the labour ward Medical Records Department. Analysis of data was done using tables, simple percentages, means and range. The necessary approval of the institutional Ethics Committee for the work was obtained.

\section{Limitations of the Study}

The investigators have no control over the quality of data collected since it is retrospective in nature. This may have account for missing data and sometimes outright loss of some relevant information like pregnancy complications that could have also acted as determinants for CS in this study.

\section{Results}

There were 636 deliveries, out of which 124 were caesarean sections. The mean age of the 124 patients during the period of the study was 28.8 years with a range of $17-44$ years, and majority of the patients $(43.5 \%)$ were in the age group of $26-30$ years (Table 1$)$, with $(82.3 \%)$ of the total patients included in this study in the age range of 21-35 years. The mean gestational age at delivery was 38.4 weeks. Of those who had CS (124), 18.5\% were nulliparous while $78.2 \%$ were multiparous, while the parity of the remaining (3.2\%) was not documented. Majority $(70.2 \%)$ of the women were booked, while $29.8 \%$ were unbooked. Most of the patients $(75.9 \%)$ delivered at term (37-42 weeks gestation), $17.9 \%$ delivered preterm and $6.3 \%$ had prolonged pregnancy (Figure $1)$.

\begin{tabular}{|l|l|l|}
\hline Age group (Years) & Frequency & Percent \\
\hline$\leq 20$ & 9 & 7.3 \\
\hline
\end{tabular}

\begin{tabular}{|l|l|l|}
\hline $21-25$ & 22 & 17.7 \\
\hline $26-30$ & 54 & 43.5 \\
\hline $31-35$ & 26 & 21 \\
\hline $36-40$ & 11 & 8.9 \\
\hline$\geq 41$ & 1 & 0.8 \\
\hline Not stated & 1 & 0.8 \\
\hline Parity & & \\
\hline 0 & 23 & 18.5 \\
\hline 1 & 44 & 35.5 \\
\hline 2 & 21 & 16.9 \\
\hline 3 & 13 & 10.5 \\
\hline 4 & 11 & 8.9 \\
\hline$\geq 5$ & 8 & 6.5 \\
\hline Not stated & 4 & 3.2 \\
\hline Booking status & & 8.1 \\
\hline Unbooked & 37 & 62.1 \\
\hline Booked elsewhere & 10 & 29.8 \\
\hline Booked & 77 & \\
\hline
\end{tabular}

Table 1: Socio-demographic characteristics of patients 2012-2014 $(\mathrm{n}=124)$.

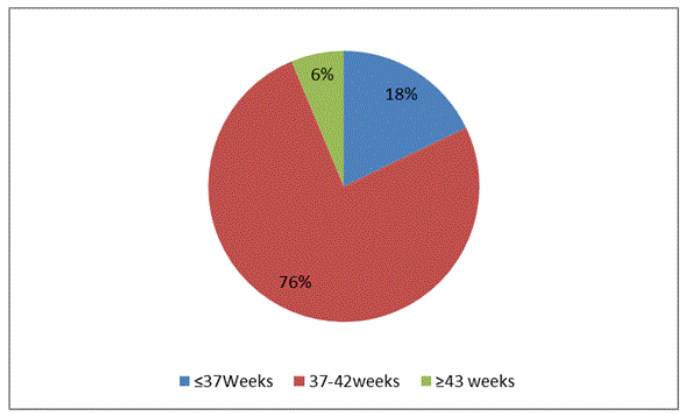

Figure 1: Gestational age at CS.

The CS rate fell marginally from $19.85 \%$ in the first year to about $19.25 \%$ in the second year (Table 2). Table 3 shows the frequency of the indications for caesarean section. Cephalopelvic disproportion (CPD) remained the commonest indication for CS accounting for $28.8 \%$ of all the patients; followed by previous (14.4\%), fetal distress (12.3\%), fetal malposition (7.5\%), fetal macrosomia. Other indications for CS at BSUTH within the study period include: antepartum hemorrhage (5.5\%), pre-eclampsia (3.4\%), and eclampsia (2.1\%) HIV/ AIDS constitutes $2.7 \%$. The least indications were elderly primigravida, previous myomectomy, chorioamnionitis and fetal malformations with each contributing $0.7 \%$. 
Page 3 of 4

\begin{tabular}{|l|l|l|l|l|l|}
\hline Type of Delivery & CS & VD & CS+VD & Yearly CS Rate\% & Overall CS Rate\% \\
\hline Sept 2012- Aug. 2013 & 52 & 210 & 262 & 19.85 & \multirow{2}{*}{19.5} \\
\hline Sept. 2013-Aug. 2014 & 72 & 302 & 374 & 19.25 & \\
\hline Total & 124 & 513 & 636 & & \\
\hline
\end{tabular}

Table 2: Yearly rate of cs and type of delivery, 2012-2013.

\begin{tabular}{|c|c|c|}
\hline Indication & Frequency & Percent \\
\hline $\begin{array}{l}\text { Previous } \\
\text { Section }\end{array}$ & 21 & 14.38 \\
\hline $\begin{array}{l}\text { Cephalopelvic } \\
\text { Disproportion }\end{array}$ & 42 & 28.77 \\
\hline Fetal Distress & 18 & 12.33 \\
\hline Fetal Malposition & 11 & 7.53 \\
\hline Antepartum Hemorrhage & 8 & 5.48 \\
\hline Fetal Macrosomia & 8 & 5.48 \\
\hline Multiple pregnancy & 7 & 4.79 \\
\hline HIVIAIDS & 6 & 4.11 \\
\hline Hypertension in Pregnancy & 5 & 3.42 \\
\hline Breech Presentation & 4 & 2.74 \\
\hline Eclampsia & 3 & 2.05 \\
\hline Failed Induction of labor & 3 & 2.05 \\
\hline $\begin{array}{ll}\text { Intrauterine } & \text { growth } \\
\text { retardation } & \end{array}$ & 3 & 2.05 \\
\hline Florid genital warts & 2 & 1.37 \\
\hline Cord Prolapse & 1 & 0.68 \\
\hline Elderly Primigravida & 1 & 0.68 \\
\hline Previous Myomectomy & 1 & 0.68 \\
\hline Chorioamnionitis & 1 & 0.68 \\
\hline Hydrocephalus & 1 & 0.68 \\
\hline Total & 146 & 100 \\
\hline
\end{tabular}

Table 3: Indications for caesarean section.

\section{Discussion}

The CS rate recorded in this study was $19.5 \%$ which is outside the $5-10 \%$ recommended by WHO. It is also higher than $10.5 \%$ earlier recorded in a similar study in a secondary level care hospital in Makurdi [16], 10.4\% in Awka [17] and 11.85\% recorded in Maiduguri [13], but less than the rates of $20.8 \%$ to $34.5 \%$ recorded in some tertiary institutions in Nigeria [17-19]. It is however, similar to $18 \%$ reported from Jos, Northern Nigeria [20]. The highest reported rate in Nigeria was $35.9 \%$ at a tertiary hospital in Oshogbo in Southwestern Nigeria [21]. There is a high rate of reported CS in the developed

countries of the world. In the United States it is said to have leveled off at $32.8 \%$ in 2010 and 2011 [14,22], while that in England, Wales and Northern Ireland is $20 \%$ [21].

Although the CS rate is said to vary from region to region and from one country to another [16], the rate seen in our study is quite high especially when juxtaposed against a region where large family size is desired and idolized for various reasons ranging from care of the parents at old age, to increased source of income and higher production on the farm; all which are likely to worsen the future reproductive health problems of the mothers as well as the perinatal morbidity and mortality. It was however, observed that the yearly rate reduced from $19.9 \%$ in the first year to $19.3 \%$ in the second year, in spite of the reported increase of the CS rate worldwide. Whether this marginal decline will be sustained is not clear. But the high rate in this study may be as a result of the referral and high risk nature of our hospital in this region. This may explain why majority of the patients (59.7\%) who had CS were booked. They could have been referred to the hospital for booking as high risk cases. Those who had unsatisfactory care in their previous deliveries including CS in other private and secondary level government hospitals may have also changed in their subsequent pregnancy and presented at BSUTH. This is further exemplified in the fact that $78.2 \%$ of the patients were multiparous with only $8.9 \%$ nulliparous (Table 1 ).

With regard to the indications for CS 142 multiple responses were reported. Of the total, the commonest indication was CPD which accounted for $28.8 \%$ of all the reasons reported for CS. This is at variance with studies from Eastern Nigeria [18,23], where previous CS has overtaken CPD as major indication for CS in the area, which may be explained by the improved standard of living and availability of health care and CS in the region. It is however in agreement with other reports in Nigeria. [18,24,25]. It has been estimated that 500 million women in developing countries are stunted as a result of malnutrition in childhood [17], resulting in inadequate development of the bony pelvis in many of them and subsequent reproductive health challenges during labour and delivery.

Majority of the women who had CS were in the age range 21- 35 years, which agrees with other reports $[26,27]$. This represents the period of highest reproductive performance and we believe the problems likely to result in operative abdominal delivery are more to be seen in this age bracket. Of those who had CS $78.2 \%$ were multiparas, which are contrary to reports from other researchers indicating a higher rate in the nulliparous $[18,25]$. This may have been due to the high parity nature of the population as well as the position of the hospital as a referral centre in the region which is likely to receive high risk cases including the repeat CS cases. Foetal distress also contributed $12.3 \%$ to the indications for CS and this may have been due to the reliance on intermittent auscultation and cardiotocograghic monitoring, in the absence of foetal scalp electrodes for sampling in our hospital. 
Apart from the desire for large family size and the high risk and referral nature of our hospital, some of the factors responsible for the increased need for CS and the high CS rate observed here, despite a strong aversion for this mode of delivery among women in our region may include; the high incidence of CPD due to malnutrition in the childhood years, low thresh hood for the procedure due to the absence of adequate labour monitoring devices such as foetal scalp electrodes for blood sampling and inadequate utilization of vagina birth after caesarean (VBAC). Others include inadequate counselling of women on future reproductive risks before the first CS, pressure by health personnel for women to accept CS and the side effects of common labour interventions such as labour induction.

To reduce CS rate in our hospital and similar institutions, deliberate effort should be made to improve on the facilities available and the employment and training of high caliber staff. The use of external cephalic version and the reduction of above mentioned high risk procedures may also help to reduce the CS rate in our hospitals. Some of the drawbacks of our study include the low volume of patients, the small duration of the study period, inadequate documentation and outright loss of some data (which may be resolved with the modern electronic health records) all which are common with similar studies.

\section{Acknowledgements}

We are highly grateful to Dr. Audu Onyemocho who carefully helped in the review of this paper, Mr. Sesugh koko for working on the statistical analysis, Mr. Tehemba Ihom and Terlumun Swende for their patience during the production of this manuscript. We appreciate the Consultants who permitted us the use of their patients for this work. To all those who helped in one way or the other during the course of this paper, we say a big thank you.

\section{References}

1. Kwawukume EY (2000) caesarean section In: Comprehensive Obstetrics in the tropics. Kwawukume EY, Emoveyan E, editors, Asante and Hittche Printing Press Limited 321-329.

2. Mutihir JT, Daru PH, Ujah IA (2005) Elective Caesarean Sections at Jos University Teaching Hospital. Trop J Obstet Gyaenecol. 22: 39-41.

3. Gibbons L, Belizan JM, Laver JA, Betran AP, Merialdi M (2010) The Global Numbers and Costs of Additionally Needed and Unnecessary Caesarean Sections Performed Per Year; Overuse as a Barrier to Universal Coverage. World Health Report Backgound paper, No 30.

4. Dumont A, de Bernis L, Bouvier-Colle MH, Bréart G; MOMA study group (2001) Caesarean section rate for maternal indication in subSaharan Africa: a systematic review. Lancet 358: 1328-1333.

5. Ronsmans C, Van Damme W, Filippi V, Pittrof R (2002) Need for caesarean sections in west Africa. Lancet 359: 974.

6. De Brouwere V, Dubourg D, Richard F, Van Lerberghe W (2002) Need for caesarean sections in west Africa. Lancet 359: 974-975.

7. Betrán AP, Merialdi M, Lauer JA, Bing-Shun W, Thomas J, et al. (2007) Rates of caesarean section: analysis of global, regional and national estimates. Paediatr Perinat Epidemiol 21: 98-113.

8. Althabe F, Sosa C, Belizán JM, Gibbons L, Jacquerioz F, et al. (2006) Cesarean section rates and maternal and neonatal mortality in low-, medium-, and high-income countries: an ecological study. Birth 33: 270-277.

9. Villar J, Valladares E, Wojdyla D, Zavaleta N, Carroli G, et al. (2006) Caesarean delivery rates and pregnancy outcomes: the 2005 WHO global survey on maternal and perinatal health in Latin America. Lancet 367: 1819-1829.

10. Ronsmans C, Holtz S, Stanton C (2006) Socioeconomic differentials in caesarean rates in developing countries: a retrospective analysis. Lancet 368: 1516-1523.

11. Belizán JM, Althabe F, Cafferata ML (2007) Health consequences of the increasing caesarean section rates. Epidemiology 18: 485-486.

12. Turner MJ (1997) Delivery after one previous cesarean section. Am J Obstet Gynecol 176: 741-744.

13. Geidam AD, Audu BM, Kawuwa BM, Obed JY (2009) Rising trend and indications of caesarean section at the university of Maiduguri teaching hospital, Nigeria. Ann Afr Med 8: 127-132.

14. Childbirth Connection Why is the National US Cesarean Section Rate so high? 2012

15. Declercq E, Menacker F, Macdorman M (2006) Maternal risk profiles and the primary cesarean rate in the United States, 1991-2002. Am J Public Health 96: 867-872.

16. Swende TZ, Agida ET, Jogo AA (2007) Elective caesarean section at the Federal Medical Centre Makurdi, north central Nigeria. Niger J Med 16: 372-374.

17. Ikeako IC, Nwajiaku I, Ezegwui Hu (2009) Caesarean section in a Secondary Health Hospital in Awka, Nigeria. Niger Med J. 50: 64-67

18. Okezie AO, Oyefara B, Chigbu CO (2007) A 4-year analysis of caesarean delivery in a Nigerian teaching hospital: one-quarter of babies born surgically. J Obstet Gynaecol 27: 470-474.

19. Igberase GO, Ebeigbe PN, Andrew BO (2009) High caesarean section rate: a ten year experience in a tertiary hospital in the Niger Delta, Nigeria. Niger J Clin Pract 12: 294-297.

20. Aisien AO, Lawson JO, Adebayo AA (2002) A five year appraisal of caesarean section in a northern Nigeria university teaching hospital. Niger Postgrad Med J 9: 146-150.

21. Adekanle DA, Adeyemi As, Fasanu AO (2013) Caesarean Section at a tertiary institution in Southwestern Nigeria- A 6-year audit. Open Journal of Obstetrics and Gynecology 3: 357-361

22. Hamilton BE, Martin JA, Ventura SJ (2012) Births: Preliminary data for 2011. Natl Vital stat Rep 61: 1-19.

23. Okafor CI, Onwosulu DN (2006) Rising caesarean section rate: Any hope for decline? NAUTH Nnewi experience. Nigerian Medical Journal 47: 38-40

24. Iyaiya MA, Aboyeji PA (2001) Caesarean delivery: The Trend over a Ten year Period at Ilorin, Niheria. Nigerian Journal of Surgical Research 3: 11-17

25. Efetie RE, Umezulike AC, Agboghoroma CO (2006) caesarean Section at the National Hospital, Abuja. 1999-2001 ANMINS 3: 34-39

26. Okonta PI, Oforide VO, Okogbenin SA (2003) Caesarean Section at the University of Benin Teaching Hospital Revisited. Trop J Obstet Gynaecol 20: 63-66

27. Bala S, Alih B, Nwanmut DD, Bako EA, Mustapha SS (1999) Caesarean section at the Nigerian National Petroleum Corporation Industries Clinic, Kaduna, Nigeria. Orient J Med 11: 39-42. 